\title{
DEVELOPING A MONITORING WORKFLOW FOR THE TEMPLES OF JAVA
}

\author{
U. Herbig ${ }^{1 *}$, L. Stampfer ${ }^{1}$, D. Grandits ${ }^{2}$, I. Mayer ${ }^{1}$, M. Pöchtrager ${ }^{1}$ Ikaputra $^{3}$, A. Setyastuti ${ }^{4}$ \\ ${ }^{1}$ TU Wien, Inst. of History of Art, Building Archaeology and Restoration, Research Unit Building History and Building \\ Archaeology (herbig, lukas.stampfer, irmengard.mayer, markus.poechtrager)@tuwien.ac.at \\ ${ }^{2}$ TU Wien, Inst. of History of Art, Building Archaeology and Restoration, Research Unit of Monument Preservation \\ (doris.grandits@tuwien.ac.at) \\ ${ }^{3}$ Department of Architecture and Planning, Research Group Architecture Universitas Gadjah Mada, Yogyakarta, Indonesia \\ (ikaputra_2001@yahoo.com) \\ ${ }^{4}$ Balai Pelestarian Cagar Budaya DIY (kebudayaan@kemdikbud.go.id)
}

Commission II, WG II/8

KEY WORDS: Photogrammetry, Recording, Matching, TLS, Monitoring, hybrid methods in photogrammetry, Indonesian Temples

\begin{abstract}
:
Indonesia is rich in cultural diversity. Although Islam is the main religion, the most famous sites in Indonesia are the ancient temples (Candis) on Java and Bali. The Candis in Java represent a challenging ancient architectural heritage and are important features for the Javanese population to identify with their own culture, even today as the Buddhist and Hindu religions have almost disappeared from everyday life. The temples of Borobudur and Prambanan are on the UNESCO World Heritage List and are among Indonesia's most popular tourist destinations. In addition, there are numerous smaller temples and temple complexes for whose preservation is challenged by recurring earthquakes. Continuous monitoring of the monuments, especially with regard to structural stability, is therefore essential. In cooperation of the TU Wien with the Universitas Gadjah Mada, Yogyakarta and local authorities, a possible workflow for a future surveying and continuous monitoring of the monuments was tested. With the help of 3D laser scanning and photogrammetry the most reliable and economical method for the continuous observation of the temples shall be developed taking into account the local conditions. In a cooperation of lecturers of the participating universities and students, as well as experts of the responsible temple authority ten temples were measured in order to test the envisaged workflows and their reliability This paper shows the approach and exemplary results.
\end{abstract}

\section{INTRODUCTION}

\subsection{Indonesia and its cultural heritage}

The Indonesian archipelago consists of 17,000 islands, of which only about one third are inhabited. It is the world's largest island state and the fourth most populated nation in the world. The capital Jakarta on the island of Java is the most densely populated conurbation in Indonesia. An important source of income is tourism, which is largely based on the diverse cultural heritage.

The numerous temples still bear witness to the eventful history of the island. The so-called Candis hold an important position in the cultural history of Southeast Asia and are among the most outstanding examples of Buddhist and Hindu architecture. In addition, Javanese religious monuments represent a syncretism that can be regarded as an essential feature of the Indonesian way of life. Among the most famous temples in the world are Borobudur, one of the largest Buddhist temples, and the Hindu temples of Prambanan. Both temples have been included in UNESCO's World Heritage List for their outstanding universal value (OUV). Because of their OUVs, these sites are particularly well documented and are under monument preservation care. (eg. Suwardhi et al., 2015 or Koyama et al., 2015) In addition to these well-known sites around 280 smaller and larger temples or temple ruins are located throughout the plains in the centre of Java, which consists on the administrative districts of Yogyakarta Special Region and Central Java. These sites are also of local economic importance, but because of their large number and geographical distribution, they represent a challenge in terms of preservation and management.

Especially after earthquakes, many of the sites are closed for safety reasons to avoid endangering visitors. Only after a check of the structural conditions the temples are opened to public access again, which means a financial loss for many, often small communities.

For this reason - but also in order to offer a solid and economical solution for continuous monitoring - documentation procedures should be developed that allow a rapid and reliable assessment of the situation. With the further described project a procedure is to be developed, which considers the given framework conditions and means a relief for the work of the responsible authorities.

\subsection{Collaboration TU Wien UGM}

Since 2004 there has been close cooperation between the department of architecture at the Universitas Gadjah Mada (UGM), Yogyakarta and the Institute for History of Art, Building Archaeology and Restoration of TU Wien. In various projects, scientists from both institutions have worked together on research regarding architectural heritage. Topics include the documentation of Indonesia's traditional vernacular and sacral architecture, the impact of reconstruction measures on cultural heritage and society and the research and improvement of the building performance of museum buildings. 
A focus is laid on the mutual transfer of knowledge and intensive interdisciplinary collaboration. Based on this cooperation, the work on the temples around Yogyakarta, which was started with a comprehensive research on the architectural structures, could be implemented. (Lehner, 2013 and Lehner, 2017). This also laid the foundation for the collaboration with local authorities that are in charge of the monument preservation in the Yogyakarta Special Region, Balai Pelestarian Cagar Budaya Daerah Istimewa Yogyakarta (short BPCB DIY) (Cultural Heritage Conservation Center, Special Region Yogyakarta) and Dinas Kubudayaan Yogyakarta (Department of Culture Yogyakarta).

\section{BACKGROUND AND OBJECTIVES}

\subsection{Candis of Java}

The term Candi is used to describe all Buddhist and Hindu temples in Indonesia. They are monumental relics of the early historic era of Java, witnesses of its highly-developed culture in the last quarter of the first millennium $\mathrm{AD}$. Within the context of the history of architecture, Javanese Candis rank among the most outstanding building types of Buddhist and Hindu architecture and form a significant link to understanding the history of Southeast Asian culture. Well known Candis such as Borobudur and Prambanan are also among the highest-ranking tourist destinations in Java.

Candis were designed as simple stone constructions, mostly with a square ground plan, and consist of three parts, the substructure, which forms the basis a Candi, the temple's wall zone, and the temple roof, which gradually jumps back and creates a pyramid-shaped vault in the interior. (see Figure 1) The clearly architecturally accentuated tripartite division reflects the symbolic connections to their mythological significance. There are different variations of the Candis, which are mostly part of a group of buildings, which can consist of surrounding walls, gates, and accompanying smaller temples.

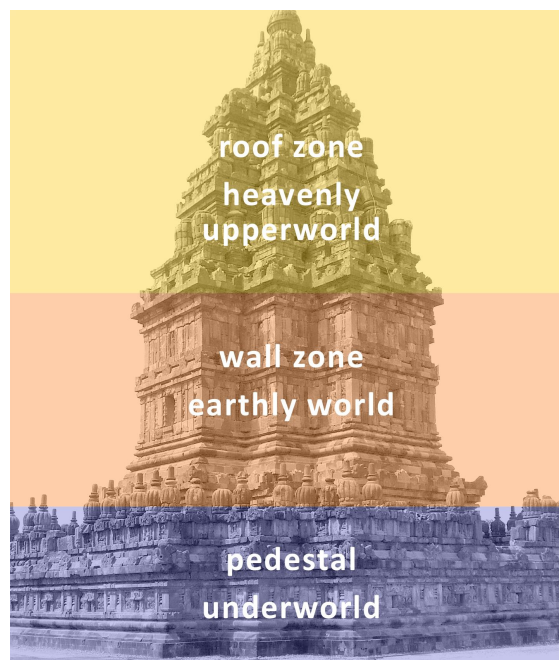

Figure 1. The tripartite symbolic concept: Prambanan, Candi Śiva Loro Jonggrang, elevation with overlaid spheres (Lehner, 2013)

Their position within the landscape and their architectural design was determined by a series of socio-cultural, religious and economical factors. The highest density of temples can be found in the centre of Java.

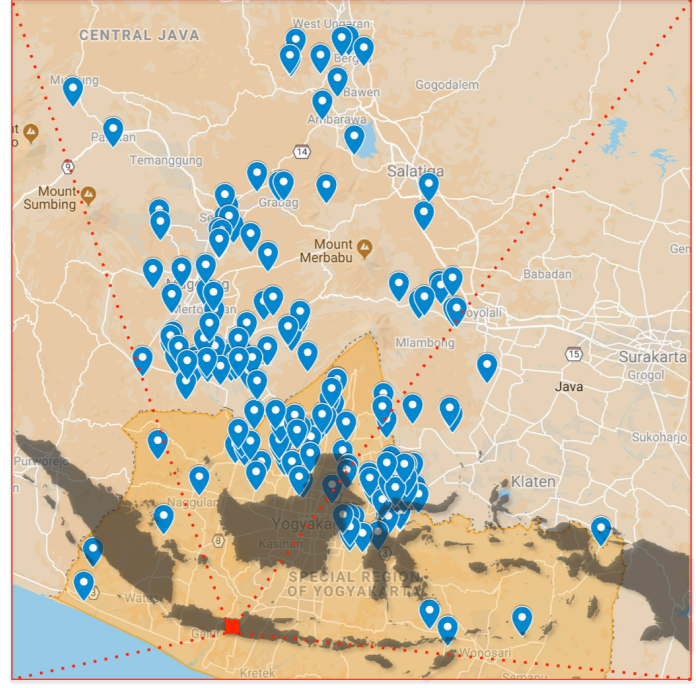

Figure 2. Distribution of Candis in the center of Java (based on data by Degroot, 2009)

An essential aspect in the scientific approach to the temples in Indonesia is the fact that earthquakes and volcanic eruptions, some of which are severe, repeatedly hit the region. In this way most of the Candis as we can see them today are already result of a reconstruction. (Lehner, 2017)

\subsection{Monument preservation and protection Indonesia}

In Indonesia, the Ministry of Education and Culture has the administrative responsibility for the preservation of historical monuments. In 1931 the Dutch-Indian Government issued the Monumenten Ordonnantie No.19 which marked the beginning of the legal protection of the cultural heritage in Indonesia. Following Indonesia's independence in 1945, cultural heritage was incorporated into the constitution of the Republic of Indonesia, with the legal framework still focusing on tangible cultural heritage until it was amended by the "Indonesian Cultural Law" in 2011. With this new law also cultural landscapes and intangible heritage is considered. (Fitri et al., 2016) But the law only provides the framework, while detailed regulatory conditions or technical regulations are missing. (Febriyanti \& Purwestri, 2013) Cultural agendas are the objective of two ministries. While the Ministry of Tourism, Arts and Culture has the role of using the cultural diversity and wealth of the country as an attraction for tourists, the Ministry of Education and Culture underlines its mission to carry out training, development, protection and usage of the cultural heritage and thus provide upstream measures.

The implementing administrative units are managed by the General Directorate of Culture (Direktorat Jenderal Kebudayaan). 12 Cultural Heritage Conservation Centers all over Indonesia (Balai Pelestarian Cagar Budaya) are in charge for the technical implementation of monument preservation agendas.

\subsection{Seismic activities}

Especially at the Pacific Ring of Fire, a tectonic subduction zone, environmental catastrophes such as earthquakes, volcanic eruptions and the resulting tsunamis are foreseeable. In Indonesia, earthquakes occur almost daily at levels five to six of the Richter scale. In the last 100 years, 175 earthquakes with a strength of at least seven have been measured in the Indonesian 
area. The preservation of the cultural heritage of such problematic regions must be carefully considered. One approach is to adequately record the monuments in order to prevent them from extinction through natural disasters. Digital data recordings can help to virtually capture the monuments and in the event of a disaster this information can be helpful for securing and assessing the potential danger.

\subsection{Objectives}

One of the aims of the cooperation between UGM and TU Wien is the documentation of architectural heritage. With a project for the recording of a museum in Yogyakarta 3D laser scanning has been introduced for the recording of buildings in research and teaching. (Herbig et al., 2017) Within the framework of this project, at the suggestion of the BPCB DIY, Candi Sari was surveyed. Resulting from this a cooperation with the authorities was established which forms the basis for all further activities.

The main objective is the development of an integrated monitoring system that allows fast recording and reliable controlling based on a high-precision recorded data set that serves as reference material. To fulfil this task, the most efficient tools and workflows for the implementation of survey, processing and analysis have to be found. In addition, future operators must also be trained accordingly in order to carry out the individual tasks.

The specific objective of the project described in this paper is therefore to analyse the framework conditions on site, in terms of the available technical requirements of hardware and software as well as the state of knowledge of future potential users. Based on this, various methods were tested on site, the results were summarized and analysed, and a first draft for a possible future workflow was developed.

\section{METHODOLOGY AND WORKFLOW}

A combined application of terrestrial laser scanning (TLS) and photogrammetry was chosen for the methodical approach. As already described by different authors (e.g. Grussenmeyer et al., 2012) the combination of the two techniques bear their advantages and seem appropriate for the given task. At UGM the Faculty of Engineering, Department of Architecture and Planning is working on the preservation and management of heritage. Future tasks for the documentation, preservation and management could be accomplished in cooperation with archaeologists working at the BPCB DIY.

The aim of the joint work on site was to check the available possibilities and the existing equipment and to present the necessary tools to the future users. The following workflow was implemented to enable the first step of the training and to create a future working environment.

- Selection of suitable objects

- Preparation of different hard and software

- Theoretic introduction to the surveying techniques

- Survey of the temples using TLS and different cameras for a photogrammetric usable recording

- Introduction to the post-processing tools

- Processing of the data by experts and participants

- Analysing the process

- Outline a workflow for the future monitoring

- Additional surveys

- Analysis of the material

- Adaptation of the workflow

\subsection{Documentation of Candis around Yogyakarta}

The selection of the objects was based on their size, accessibility and state of preservation. The focus was on the small temples around Yogyakarta and limited to objects in this district, since only these are administered by the responsible authority involved in this cooperation. Records were made during a series of research campaigns in various extent, with most of the work being carried out during a 3-week workshop.

3.1.1 Initial documentation of Candi Sari: In 2016, a project was done on Museum Affandi in the heart of Yogyakarta. Due to good progress the team of TU Wien was able to also collect a full set of terrestrial laser scanning data on Candi Sari, located not far from the initial project area and close to the office of the $B P C B D I Y$. The device in use was a Riegl VZ400 with a mounted single-lens reflex (SLR) camera. The temple was covered with 9 exterior and 12 interior scan positions. In addition, images were taken for each scan position with the camera fixed to the scanner in order to colour the point cloud.

3.1.2 Workshop on building documentation: During the 2017 workshop on building documentation, participants from both TU Wien and UGM have been working in mixed teams on documenting a series of Candis in the Special Region of Yogyakarta. To accomplish this endeavour equipment of TU Wien, the company Riegl and the $B P C B D I Y$ was in use. Under supervision of members of TU Wien the aim was to test different laser scanning devices as well as results of different cameras and software for image matching. All together 10 temples were surveyed using a terrestrial laser scanner and photogrammetry (Figure 3). The smaller temples were surveyed entirely whereas from the bigger ones like Candi Barong the overall layout of the temple complex or the main temple building were documented.

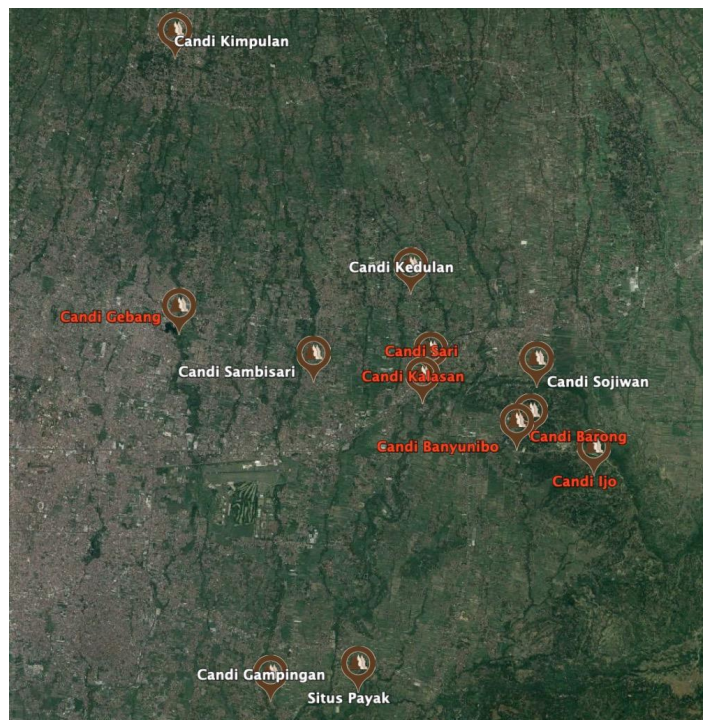

Figure 3. Overview of the sites surveyed during the campaign 2017. 
3.1.3 Aerial photogrammetry documentation 2018: To increase coverage of the Candis documented in recent years, some time of a 2018 project in the area of Yogyakarta was used to survey some of the objects using aerial photography via a consumer-sized drone. Within two days 6 temples were surveyed that have already been worked on in previous years to increase data coverage from above. (labelled in red Figure 3) To scale the data acquired by photogrammetry a traverse was laid out around the objects consisting of markers on the ground with a $40 \times 40 \mathrm{~cm}$ extent. When available the traverse was also connected to the local cadastral points to be able to continue measurements in future campaigns.

\subsection{Devices in use}

To find the most appropriate tools for the future workflow different surveying instruments were in use for the documentation of the 10 Candis. To be able to combine the different data sets deriving from the laser scan survey and the photogrammetry for each temple a local tacheometric polygon net - based on surveys done by the BPCB DIY - was prepared. Unfortunately no geo referenced coordinates were available for the tacheometric survey.

3.2.1 Laser scanners: For a better comparison of data and workflows different laser scanner were used for the 3D survey. In addition, the laser scanners use different measuring methods time-of-flight and phase shift - for distance measurement, which allows analysis on the level of building research.

\begin{tabular}{|l|l|l|l|l|}
\hline & $\begin{array}{l}\text { Riegl } \\
\text { VZ400 }^{1}\end{array}$ & $\begin{array}{l}\text { Riegl } \\
\text { VZ10003 }^{1}\end{array}$ & $\begin{array}{l}\text { Zoller Fö̈hlich } \\
5010 \mathrm{C}^{2}\end{array}$ & $\begin{array}{l}\text { Faro } \\
\text { Focus 3D X 330 }\end{array}$ \\
\hline & time-of-flight & time-of-flight & $\begin{array}{l}\text { high-speed phase- } \\
\text { based }\end{array}$ & \\
\hline 1 & $1,5 \mathrm{~m}-600 \mathrm{~m}$ & $2,5 \mathrm{~m}-1400 \mathrm{~m}$ & $0,3 \mathrm{~m}-187,3 \mathrm{~m}$ & $0,6 \mathrm{~m}-30 \mathrm{~m}$ \\
\hline 2 & $3 \mathrm{~mm}$ & $5 \mathrm{~mm}$ & $0,5-10 \mathrm{~mm}$ & $0,15-0,4 \mathrm{~mm}$ \\
\hline 3 & $5 \mathrm{~mm}$ & $8 \mathrm{~mm}$ & $0,007^{\circ} \mathrm{rms}$ & $2 \mathrm{~mm}$ \\
\hline 4 & $0,0005^{\circ}$ & $0,0005^{\circ}$ & $0,0004^{\circ}$ & $0,009^{\circ}$ \\
\hline 5 & $0,0005^{\circ}$ & $0,0005^{\circ}$ & $0,0002^{\circ}$ & $0,009^{\circ}$ \\
\hline 6 & $100^{\circ}\left(+60^{\circ}-40^{\circ}\right)$ & $100^{\circ}\left(+60^{\circ} /-40^{\circ}\right)$ & $320^{\circ}$ & $300^{\circ}$ \\
\hline 7 & $360^{\circ}$ & $360^{\circ}$ & $260^{\circ}$ & $360^{\circ}$ \\
\hline
\end{tabular}

Table 1. Deployed laser scanners: 1 - range; 2 - precision; 3 accuracy; 4 - vertical resolution; 5 - horizontal resolution; 6 vertical scan angle range; 7 - Horizontal Scan Angle Range

3.2.2 Cameras: In order to compare the differences in the quality of the results the aim was to use a great selection of cameras. For the production of the digital image material for photogrammetric processing and generation of 3D spatial data, different hardware with different quality was tested.

\begin{tabular}{|l|l|l|l|l|}
\hline Modell & Resolution $(\mathrm{px})$ & $\begin{array}{l}\text { sensor size } \\
(\mathrm{mm})\end{array}$ & lense & $\begin{array}{l}\text { surveyed } \\
\text { temples }\end{array}$ \\
\hline Canon EOS 5D Mark III & $5760 \times 3840$ & $36 \times 24$ & $16-35 / 24$ & 2,6 \\
\hline Canon EOS 5D Mark II & $5616 \times 3744$ & $36 \times 24$ & 14 & $1,5,8$ \\
\hline Canon EOS 70D & $5472 \times 3648$ & $22,5 \times 15$ & $18-135 / 10-24$ & 1,5 \\
\hline Canon EOS 500D & $4752 \times 3168$ & $22,3 \times 14,9$ & $18-200 / 20$ & $3,4,10$ \\
\hline Canon EOS 600D & $5184 \times 3456$ & $22,3 \times 14,9$ & $18-200$ & 5 \\
\hline Canon EOS 1100D & $4272 \times 2848$ & $22,2 \times 14,7$ & $18-55$ & 9 \\
\hline Canon EOS Kiss X5 & $5184 \times 3456$ & $22,3 \times 14,9$ & $18-55$ & 9 \\
\hline
\end{tabular}

\footnotetext{
${ }^{1}$ provided by Riegl Laser Management Systems

2 provided by TU Wien, Department of Geodesy and

Geoinformation

${ }^{3}$ provided and operated by BPCB DIY
}

\begin{tabular}{|l|l|l|l|l|}
\hline Canon EOS M2 & $5184 \times 3456$ & $22,3 \times 14,9$ & $18-55$ & 1 \\
\hline FUJIFILM X-A2 & $4896 \times 3264$ & $23,6 \times 15,6$ & $16-50$ & $3,4,10$ \\
\hline GoPro HERO5 Black & $4000 \times 3000$ & $6,17 \times 4,55$ & F 2,97 & 1 \\
\hline iPhone SE & $4032 \times 3024$ & $4,92 \times 3,69$ & F 2.2 & $1,5,8$ \\
\hline Olympus VR350, D755 & $4608 \times 3456$ & $6,16 \times 4,62$ & $24-240$ & 2,6 \\
\hline Samsung SM-J320G & $3264 \times 2448$ & & F 2.2 & 5 \\
\hline SONY DSC-R1 & $3888 \times 2592$ & $21,5 \times 14,4$ & $14,3-71,5$ & 5 \\
\hline Sony HDR-CX405 & $1920 \times 1080$ & $4,32 \times 2,43$ & F 1,9-57 & 9 \\
\hline Xiaomi - Redmi Note 2 & $3120 \times 4160$ & & F 2,2 & 4,10 \\
\hline
\end{tabular}

Table 2. Deployed cameras; surveyed tempels: 1 - Banyunibo; 2 - Barong; 3 - Gampingan; 4 - Gebang; 5 - Ijo; 6 - Kalasan; 7 Kedulan; 8 - Kimpulan; 9 - Sambisari; 10 - Situs Payak

Not all data has been used for the analysis so far. Prepared material will be made available for further analysis, but also for monitoring purpose.

3.2.3 Drone: To capture images from above and increase coverage of data in areas difficult to cover from the ground a UAV came to use. Guided by a local operator a drone of the model DJI Phantom 3 pro was deployed. Equipped with a FC300s camera images with a resolution of $4000 \times 2250$ pixels (approximately $9 \mathrm{MP}$ ) were taken from various angles. Maximum resolution of the camera would be 4000x3000 pixels (approximately 12MP), but settings set to a limited resolution were only discovered after the capture - all areas were covered nonetheless. With using single image photography instead of video capturing also GPS positions of the drone at the time of the image are stored into the metadata. The values of longitude, latitude and height are later used within the post-processing software to coarsely define the exterior orientation of the camera.

\subsection{Post-processing}

To process the data collected on site into comparable models different software came to use. To start with each of the laser scanners in operation comes with an obligatory use of its own manufacturer-designed program to process the scans. Therefore $\mathrm{Z}+\mathrm{F}$ Lasercontrol and Riegl RiScan came to action to register the individual scans to a joined point cloud. Further Agisoft Photoscan Professional was at hand to process the captured images into a model using image match. Within the workshop setup the cloud-based service Autodesk ReCap was also tested, but was abandoned quickly due to its lack of possibilities to control the outcome of the model.

\subsection{Combination of data}

In order to achieve a better output, the individually used application techniques are increasingly replaced by combinations of these methods. Therefore, data collected by both laser scanning and image matching were merged into one point cloud model.

For that purpose again RiScan came to use. While the point cloud resulting from drone image matching in Agisoft Photoscan was already put to scale using the traverse laid out around the objects, the ICP (iterative closest point) algorithm provided within RiScan has proven itself useful. Beside the relocation, it further allows the option of scaling the model within the process so it can perfectly fit the reference. 


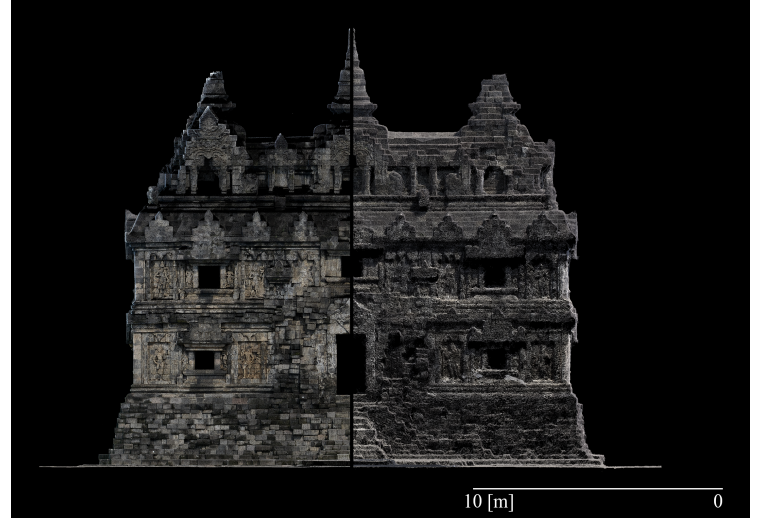

Figure 4. Orthoview of the Candi Sari point cloud from both laser scanning (left) and image matching of drone images (right)

\subsection{Point cloud analysis}

Beside the collection and combination of data the aim of this study further was to analyse the material and gain understanding about levels of accuracy. Especially in the prospect of using such data for monitoring purposes - e.g. assessments of structural changes and resulting dangers - it is of high importance to priorly to know about possibilities and limitations of the techniques proposed for such workflows. Therefore the open-source software CloudCompare came to use to analyse and visualise properties and qualities of the point cloud data.

\section{RESULTS}

\subsection{Case study: Candi Sari}

To present examples of quality of material acquired on site, an analysis of one exemplary Candi that was continuously worked on will be shown in this paper. Candi Sari was chosen to be used in such a case study as the compact and almost completely intact structure can be seen as an ideal example for a study object.

\subsection{Point cloud density}

By calculating the number of neighbours of a point within a certain volumetric distance, a measure of density can be visualised. Doing so for both laserscan and photogrammetric data, advantages and disadvantages in certain geometric configurations can be discovered. This can be helpful to acquire an understanding about the ideal areas of application for each individual method of documentation.

4.2.1 Laserscan: As can be seen in Figure 5 (top) density within the laser scanning model is varying in a way as can be expected for this method. The exterior covered by a total of about 54 million points (plus 267 million interior), areas further away from ground level show reduced density compared to lower parts. Also the right side of shown facade is covered with fewer points, as the closest scan was acquired from an angle less frontal than on the left side.

Considering that many of the areas show densities of more than 50 up to 70 neighbours around one point within a $0.02 \mathrm{~m}$ sphere, a point density in the sub-mm resolution can be calculated. This exceeds largely what is defined as LOD3 by Suwardhi et.al., 2015 for the UNESCO World Heritage Site - Borobudur. This was possible due to the previous mentioned compact volume and small extent of Candi Sari and would prove much more difficult for structures like Borobudur.

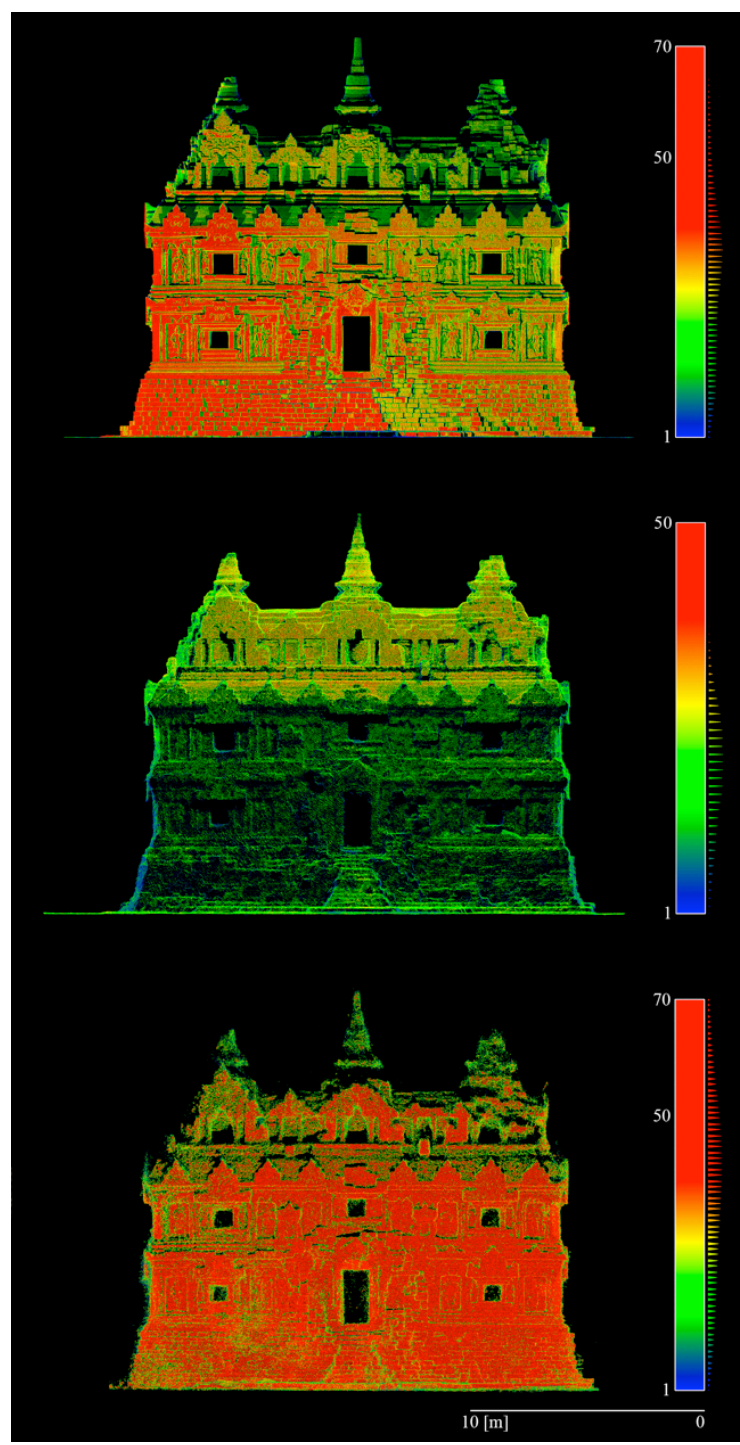

Figure 5. False-colour orthoview of the Candi Sari laser scanning (top), drone photo image match (middle) and handheld photo image match (bottom) point cloud representing the number of neighbours within a sphere of a radius $\mathrm{r}=0.02 \mathrm{~m}$; red showing maximum density with $50+$ neighbours

4.2.2 Imagematch drone: To complement the point cloud in areas that are hard to survey with a TLS, 77 drone images were taken to be processed into a point cloud of 19 million points by image matching (see Figure 4 right). The analysis of number of neighbours, analogous to the one done for the laser scanning data, clearly shows the focus that was directed to the upper parts of the Candi to cover the areas of less density in the laser scan. (see Figure 5 middle) Said regions also reach the 50+ number of neighbours, completing the whole exterior surface with a coverage of sub-mm resolution. 
4.2.3 Image match handheld camera: The graphic representation of the density analysis from handheld photography image matching shows a high resolution of points especially in the lower areas that are easily visible from the ground. (see Figure 5 bottom) With 97 camera positions and a resulting point cloud of 140 million points the data exceeds both laser scanning and drone image matching largely in number of points. Nevertheless, despite showing high density, this is not necessarily an expression of quality, as was evaluated separately and will follow later.

\subsection{Iterative closest point algorithm}

Using the laser scanning data as reference and matching the photogrammetric model to size and location a RMSD of less than $0.05 \mathrm{~m}$ could be achieved with the model from drone photography. Although the ICP (Iterative Closest Point) matching for the model of photos taken by hand was able to reach a similar RMSD, it could already be seen during the working progress that the latter photogrammetric model was of less accuracy than the one acquired by drone. To verify and visualise this observation the following chapter will present a cloud to cloud comparison aimed to expose such inaccuracies.

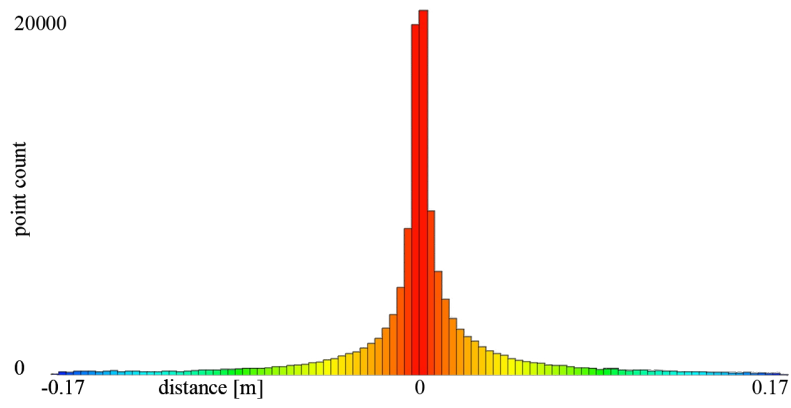

Figure 6. Result of ICP matching in RiScan showing distribution of point distances and count between laserscan and drone image match model of Candi Sari

\subsection{Cloud to Cloud comparison}

Different qualities of point clouds from different techniques of documentation could already be observed during the working process. Especially in terms of accurate representation of the built geometry large differences could be seen. To further analyse such observations the open-source software CloudCompare was used to compare point clouds and show areas in which they differ from each other. With laser scanning data considered to represent the geometry most accurately, point clouds resulting from both means photography, drone-supported and handheld, were compared to this primary data.

4.4.1 Drone image match to laser scan: When reviewing the analysis of cloud to cloud distance between the photogrammetric drone point cloud and the laser scan (Figure 7) some advantages and disadvantages can be recognized. First it can be seen that the area which was in Focus for the drone capture campaign appears very well aligned with the results from the laser scan.

With a minimum distance between the clouds, the area of the roof and the upper cornices appears to be reasonably supplemented with the UAV-data. As images taken primarily to supplement this area this proves that data collected with this technique are accurate enough to be used for that purpose. In the lower areas of Candi Sari some of the shortcomings of image matching become visible. While inaccuracies underneath cantilevering elements were to be expected it also seems that especially around very detailed regions of the facade results differ in larger extent.

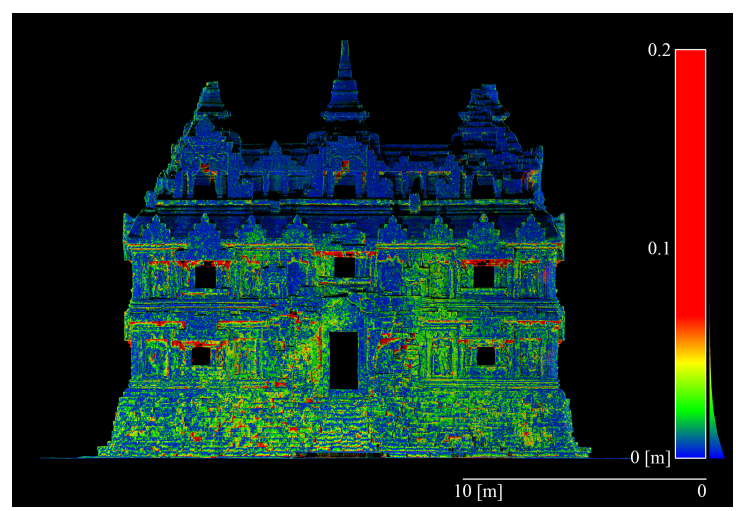

Figure 7. False-color representation of point distances between the laser scanning point cloud and the drone image match data of Candi Sari

4.4.2 Handheld image match to laser scan: While the previous cloud to cloud comparison considering drone photography showed quite expectable differences in accuracy (focus on top area, therefore vertical variations) the following analysis appears more challenging to be interpreted. The photos to generate the point cloud were taken by students after instruction but include some unfavourable choices of perspectives and lighting. As especially the side located to the left of the shown entrance facade of Candi Sari was captured facing against the sun, surfaces are very dark and low contrast on the pictures and make the matching of images much harder and more inaccurate. Since a facade of the object was not covered sufficiently, the model of the entire temple lacks accuracy. The shortcomings of this model become already visible on the left side of false-colour visualisation in Figure 7. The reasons for inaccuracies in the surfaces of stone blocks and higher accuracy in the joints, as can be seen in the bottom part of Figure 5, cannot be explained at this point but will be under further investigation.

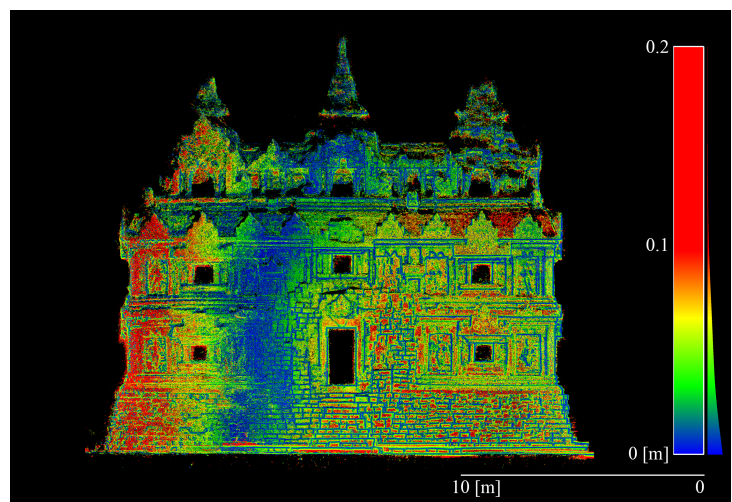

Figure 8. False-color representation of point distances between the laser scanning point cloud and the handheld image match data of Candi Sari

\subsection{Workflow}

The first outline of the planned workflow is to create a highprecision dataset for further tasks using TLS. These data will be collected by experts. $B P C B D I Y$ has the necessary equipment 
for these tasks and experienced operators to perform the laser scanning. In the first step, this task was carried out by students under the supervision of teachers. Since there are no possibilities on site to apply TLS for the roof area, a hybrid approach in combination of laser scanning and photogrammetric images using UAV must be used. The experience gained from the joint work showed that further training for this hybrid application and for the processing of the data would be beneficial.

Later, the point clouds of this basic data set are to be made available for the comparison of current control recordings. If required, plans and material for mapping (e.g. orthophoto) can be compiled from these data. For the on-going monitoring and in case of a necessary emergency admission (e.g. after a severe earthquake) photogrammetric images are to be created in order to use them by means of ICP matching to compare it with the base data set. In this case, the data acquisition should be carried out by persons responsible for the ongoing maintenance of the sites. For this purpose, the instructions for the acquisition of the images must be adapted in such a way that the reliability of the source material is ensured in any case. The evaluation of these data as well as the comparison of the results should be carried out due to the better availability of hard- and software at the $U G M$. For this purpose, a team would have to be trained to deal with the topic on an on going basis. The group is thus up to date with the latest technology and gains the necessary experience to be able to deliver the results in a short period of time.

\section{DISCUSSION}

\subsection{Reference Model}

The results presented in previous chapters allow an informed judgement about the usability of collected data as reference for a monitoring program of Candis in Central Java. As shown by analysis in Figure 5 and Figure 8, the use of a combined laser scanning and UAV supported image-matching model should deliver appropriate accuracy and coverage to be used as such reference model. ICP matching appears a valuable tool for the combination of data even in the absence of the possibility to measure fixed target points that appear in both laser scanning and image matching data.

\subsection{Photogrammetry for monitoring purposes}

In this case, the photogrammetric capture carried out by students under instruction a result that would probably not be sufficient to allow a lucid analysis to monitor structural changes after a seismic event. While the point cloud calculated with maximum resolution has an even higher density than the reference model from laser scanning, it still lacks its capability to accurately represent the built geometry. Nevertheless, with a refinement of technique and instructions for the person capturing the images, it is believed this is a goal that can be achieved with time.

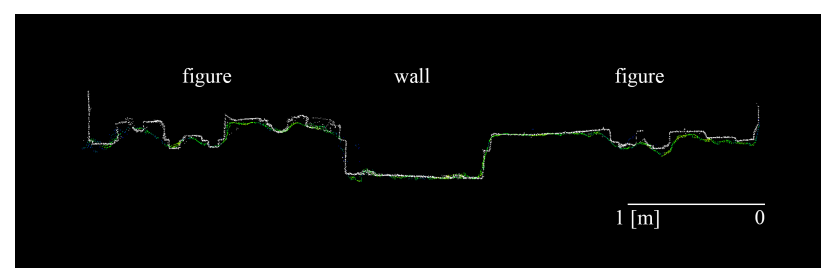

Figure 9: Horizontal section through a detail area showing differences in level of accuracy between uncomplex and elaborate geometry. Laser scanning point cloud in white, drone image matching point cloud in false-colour representing cloud to cloud distance.

It should be noted that results presented in this paper focus on exterior geometry of Candis. Temples with an interior space that can be entered, are probably to be considered the even more dangerous objects. Also, the interior spaces are likely to prove more difficult to cover with image matching as in many cases they are small and with little natural or artificial lighting. These are problems in the photogrammetric capture process that should be addressed within further projects. Still it is believed that with a refined workflow photogrammetric capture could be used as an easily accessible tool to gather a quick understanding about structural changes of Candis.

\subsection{Impact on monitoring workflow}

Already in the previous point it was stated that the recording process and, in this context, the instructions given to a nonprofessional or semi-professional carrying out the recording need to be further refined. In order to guarantee the possibility of creating a model of a Candi that shows changes in geometry after a seismic event by comparing the data, such instructions should be made available for the personal on site. To ensure the right application future users should be included in the revision of the manual.

Furthermore the analysis has shown that photogrammetric recording, if not done elaborate, has its limitations when it comes to representing a high Level of Detail (Suwardhi et al., 2015). Therefore, it would be helpful to generate a best-case photogrammetric capture with the appropriate reference model in order to have an understanding of the limitations of data and to exclude deviations in the geometry resulting from inaccuracies by the collection of the data.

\subsection{Prerequisites for implementation}

In order to implement the proposed monitoring workflow, the availability of a centralised collection of reference models is crucial. These reference models should not just be monitored by photogrammetric capture after seismic events but should also be periodically updated to have an up-to-date basis for analysis for the monitoring of changes. Local authorities, such as $B P C B$ $D I Y$, would need to incorporate such updating process of reference models into their routine.

In addition, instructions must be available to local staff, to be applied in case necessary. Ideally, the adequate capturing of photos for image matching should be tested before an emergency occurs. Also software, processing power and a qualified workforce should be available at an institution (e.g an university) to handle the processing of data collected.

\section{CONCLUSION AND FURTHER RESEARCH}

The temples of Java are an important part of Indonesia's cultural heritage. With the described approach a system for comprehensive documentation and monitoring of the objects can be developed. In order to create a practicable workflow, the feasibility of the chosen approach is considered in addition to the thorough investigation of the reliability of the data.

The close cooperation between the authority responsible for the management of the conservation of sites the Balai Pelestarian Cagar Budaya Daerah Istimewa Yogyakarta and the 
Universitas Gadjah Mada will provide a solid to provide training of future users and a comprehensible and applicable system.

As stated in this paper, there are parts and components within the proposed workflow that need to be refined. An essential part of this work is the manual for photogrammetric documentation, which creates a solid material base for post-processing that is accurate enough to analyse structural changes. Quality standards should be defined for both sides of the spectrum and determine the accuracy and density required for this workflow, taking into account the most economical way of working.

At this point, the comparison of point clouds is only visual and statistical. Although this can already provide valuable knowledge, it still depends very much on a trained person to interpret the results. Shifting the process to a numerical comparison rather than a visual one could therefore minimize the risk of misinterpretation or overlooking changes. A cooperation with the department of Geodesy at $U G M$ has been envisaged for further discussions and enlargement of possibilities.

With this work, a basis can be created for safeguarding an important part of Indonesian culture through the strength of interdisciplinary and inter-institutional cooperation.

\section{ACKNOWLEDGEMENTS}

This project is supported by funds of the Asea UniNET.

We want to express a special appreciation to the authorities, Balai Pelestarian Cagar Budaya DIY (Institute for Preservation of Cultural Heritage, DIY) and Dinas Kubudayaan Yogyakarta (Department of Culture Yogyakarta) without whose support projects of this kind would not be feasible.

We would like to express our sincere thanks to the company Riegl Laser Measurement Systems, who provided us with a 3D laser scanner for on-site recordings.

\section{REFERENCES}

Degroot, V.M.Y., 2009. Candi Space and Landscape: A Study on the Distribution, Orientation and Spatial Organization of Central Javanese Temple Remains, Doctoral Thesis, Leiden University, NLD.

Febriyanti, S. and Purwestri, N., 2013. Documenting living monuments in Indonesia: Methodology for sustainable utility. In: The International Archives of the Photogrammetry, Remote Sensing and Spatial Information Sciences, Vol. XL-5/W2, pp.617-622.

Fitri, I., Yahaya, A. and Ratna, M., 2016. Cultural Heritage and Its Legal Protection in Indonesia Since the Dutch East Indies Government Period. In: Advances in Social Science, Education and Humanities Research (ASSEHR), Vol. 81, pp.127-134. Atlantis Press.

Grussenmeyer, P., Alby, E., Landes, T., Koehl, M., Guillemin, S., Hullo, J.F., Assali, P. and Smigiel, E., 2012. Recording approach of heritage sites based on merging point clouds from high resolution photogrammetry and terrestrial laser scanning. In: The International Archives of the Photogrammetry, Remote Sensing and Spatial Information Sciences, Vol. XXXIX-B5, pp.553-558.
Herbig U, Styhler-Aydın G, Grandits D, Stampfer L, Pont U, Mayer I. 2017. Digital Workflows For Restoration And Management Of The Museum Affandi - A Case Study In Challenging Circumstances. In: The International Archives of the Photogrammetry, Remote Sensing and Spatial Information Sciences, Vol. XLII-2/W5, pp.329-334.

Koyama, T., Shimoda, I., Iwasaki, Y., 2015. Measurement of the Joint Displacement Along Masonry Wall Using Digital Photogrammetry for the Structural Stability of the Borobudur Temple, Indonesia. In: Engineering Geology for Society And Territory - Vol. 8, Preservation Of Cultural Heritage. Springer, Cham, pp. 53-57.

Lehner, E., 2013. Towards a Documentation Project on Javanese Candis, In: Insular Diversity Architecture - Culture Identity in Indonesia, Lehner, E., Doubrawa, I., Ikaputra, Eds., IVA, Vienna, pp. 19-34.

Lehner, E., 2017. Advanced survey of ancient Buddhist and Hindu temples in central Java for tracking their position within the history of Southeast Asian architecture. In: Journal of Comparative Cultural Studies in Architecture (JCCS-a), 10/2017, pp. 21-28.

Suwardhi, D., F. Menna, F. Remondino, K. Hanke, und R. Akmalia. 2015. Digital 3D Borobudur: Integration of 3D Surveying and Modeling Techniques. In: The International Archives of the Photogrammetry, Remote Sensing and Spatial Information Sciences, Vol. XL-5/W7, pp. 417-423.

Torres, J.A., Hernandez-Lopez, D., Gonzalez-Aguilera, D. and Hidalgo, M.A.M., 2014. A hybrid measurement approach for archaeological site modelling and monitoring: the case study of Mas D'Is, Penàguila. In: Journal of archaeological science, 50, pp. 475-483.

\section{References of Software used}

Agisoft Photoscan: http://www.agisoft.ca [25.06.2019]

Autodesk ReCap:

https://www.autodesk.com/products/recap/overview

[25.06.2019]

Riegl RiScan: http://www.riegl.co.at/products/softwarepackages/riscan-pro/ [25.06.2019]

Z+F Lasercontrol: https://www.zf-laser.com/Z-F-LaserControlR.laserscanner_software_1.0.html?\&L=1 [25.06.2019] 